\title{
Cortical origin of Up state onsets and offsets in anesthetized rats
}

\author{
Maria Perez-Zabalza ${ }^{1 *}$, Maurizio Mattia ${ }^{2}$, Nuria Tort ${ }^{1}$, Maria V Sanchez-Vives ${ }^{1,3}$ \\ From Twenty Second Annual Computational Neuroscience Meeting: CNS*2013 \\ Paris, France. 13-18 July 2013
}

Slow rhythms $(<1 \mathrm{~Hz})$ where Up states of sustained neural activity alternate with almost quiescent Down states, are similarly expressed by mammal brains during slow-wave-sleep (SWS) and under anesthesia [1]. Although much effort has been devoted to uncover the physiological origin of such slow oscillations (SO), it is still debated whether Up state onsets in this quasi-periodic bouncing of neural activity are driven by corticocortical synaptic interactions [1-3], or if they are due to the interplay between thalamic nuclei and cerebral cortex $[4,5]$. We addressed this issue probing neuronal and synaptic activity across all layers of primary visual cortex (V1) of rats, which showed stable Up/Down SO when anesthetized with ketamine and medetomidine.

During Up states, maximum multi-unit activity (MUA) was found at a depth of $880 \pm 80 \mu \mathrm{m}$ (mean \pm SD, $\mathrm{n}=$ 14) from cortical surface, corresponding to upper layer 5. To be able to classify events as supra/infragranular and thus to accurately identify layer 4 position, we resorted to a classical current source density (CSD) analysis looking at the earliest synaptic activation following visual stimulation [6]. This, together with a principal component analysis (PCA), allowed us to characterize Up state onsets at high spatiotemporal resolution as a stereotyped sequence of events. Firstly, in deep layers $(1260 \pm 80 \mu \mathrm{m}$, mean \pm $\mathrm{SD}, \mathrm{n}=14$ ) a CSD sink appeared highlighting the arrival of synaptic input, always followed after $10 \mathrm{~ms}$ by a MUA onset at same depths. After a variable delay between 0 and $40 \mathrm{~ms}$, MUA increased in upper layer 5 and propagated to supragranular layers. Interestingly, such upward spreading of activity from deep to more superficial layers was not altered by the inactivation of visual thalamus obtained injecting TTX in LGN (lateral geniculate nucleus). Downward transitions from Up to Down states,

\footnotetext{
* Correspondence: msanche3@clinic.ub.es

'IDIBAPS, c/. Rosselló, 149 153, 08036 Barcelona, Spain

Full list of author information is available at the end of the article
}

showed a different timing of MUA offsets across layers. We found both positive and negative time lags between MUA inactivation of upper layer 5 and deeper layers, highlighting only a weak correlation between these two events. In layer 5-6, CSD sinks followed with a rather precise delay of $50 \mathrm{~ms}$ MUA offsets at the same depth, supporting the hypothesis of a network whose preferred state is the quiescent one, despite a steady synaptic input continue to be received. Even for downward transitions the chain of events was unchanged injecting TTX in the thalamus.

The collected evidence for both Up state initiation and termination unambiguously reserves for the thalamus a marginal role, pointing out cortico-cortical connectivity as the main drive for Up/Down SO. Such cortico-cortical chat takes place in a state-dependent manner.

\section{Acknowledgements \\ Funded by BFU2008-01371, BFU2011-27094 and EU grant ICT-FET Corticonic ก. 600806 .}

\section{Author details}

${ }^{1}$ IDIBAPS, C/. Rosselló, 149 153, 08036 Barcelona, Spain. ${ }^{2}$ Istituto Superiore di Sanità, Rome, Italy. ${ }^{3}$ ICREA, Passeig Lluís Companys, 23, 08010 Barcelona Spain.

Published: 8 July 2013

\section{References}

1. Sanchez-Vives MV, McCormick DA: Cellular and network mechanisms of rhythmic recurrent activity in neocortex. Nat Neurosci 2000, 3:1027-1034.

2. Sakata S, Harris KD: Laminar structure of spontaneous and sensoryevoked population activity in auditory cortex. Neuron 2009, 64:404-418.

3. Chauvette $S$, Volgushev M, Timofeev I: Origin of active states in local neocortical networks during slow sleep oscillation. Cereb Cortex 2010, 20:2660-2674.

4. Hughes SW, Cope DW, Blethyn KL, Crunelli V: Cellular mechanisms of the slow $(<1 \mathrm{~Hz})$ oscillation in thalamocortical neurons in vitro. Neuron 2002, 33:947-958.

5. Crunelli V, Hughes SW: The slow $(<1 \mathrm{~Hz})$ rhythm of non-REM sleep: a dialogue between three cardinal oscillators. Nat Neurosci 2010, 13:9-17.
C Biomed Central

(ㄷ) 2013 Perez-Zabalza et al; licensee BioMed Central Ltd. This is an Open Access article distributed under the terms of the Creative Commons Attribution License (http://creativecommons.org/licenses/by/2.0), which permits unrestricted use, distribution, and reproduction in any medium, provided the original work is properly cited. 
6. Kenan-Vaknin G, Teyler TJ: Laminar pattern of synaptic activity in rat primary visual cortex: comparison of in vivo and in vitro studies employing the current source density analysis. Brain Res 1994, 635:37-48.

doi:10.1186/1471-2202-14-S1-P341

Cite this article as: Perez-Zabalza et al:: Cortical origin of Up state onsets and offsets in anesthetized rats. BMC Neuroscience 2013 14(Suppl 1):P341.

Submit your next manuscript to BioMed Central and take full advantage of:

- Convenient online submission

- Thorough peer review

- No space constraints or color figure charges

- Immediate publication on acceptance

- Inclusion in PubMed, CAS, Scopus and Google Scholar

- Research which is freely available for redistribution

Submit your manuscript at www.biomedcentral.com/submit

() BioMed Central 